\title{
Screening for inhibitors of mutacin synthesis in Streptococcus mutans using fluorescent reporter strains
}

\author{
Priyanka Premnath, Michael Reck', Kathrin Wittstein², Marc Stadler² and Irene Wagner-Döbler ${ }^{1 *}$ (D
}

\begin{abstract}
Background: Within the polymicrobial dental plaque biofilm, bacteria kill competitors by excreting mixtures of bacteriocins, resulting in improved fitness and survival. Inhibiting their bacteriocin synthesis might therefore be a useful strategy to eliminate specific pathogens. We used Streptococcus mutans, a highly acidogenic inhabitant of dental plaque, as a model and searched for natural products that reduced mutacin synthesis. To this end we fused the promoter of mutacin VI to the GFP+ gene and integrated the construct into the genome of S. mutans UA159 by single homologous recombination.

Results: The resulting reporter strain 423p - gfp + was used to screen 297 secondary metabolites from different sources, mainly myxobacteria and fungi, for their ability to reduce the fluorescence of the fully induced reporter strain by $>50 \%$ while growth was almost unaffected (>90\% of control). Seven compounds with different chemical structures and different modes of action were identified. Erinacine $C$ was subsequently validated and shown to inhibit transcription of all three mutacins of S. mutans. The areas of the inhibition zones of the sensor strains S. sanguinis and Lactococcus lactis were reduced by $35 \%$ to $61 \%$ in comparison to controls in the presence of erinacine C, demonstrating that the amount of active mutacins in the culture supernatants of $S$. mutans was reduced. Erinacines are cyathane diterpenes that were extracted from cultures of the edible mushroom Hericium erinaceus. They have anti-inflammatory, antimicrobial and neuroprotective effects. For erinacine C, a new biological activity was found here.
\end{abstract}

Conclusions: We demonstrate the successful development of a whole-cell fluorescent reporter for the screening of natural compounds and report that erinacine C suppresses mutacin synthesis in S. mutans without affecting cell viability.

Keywords: Streptococcus, Virulence, Mutacin, Whole-cell screening, Fluorescent reporter, Myxobacteria, Fungi, Secondary metabolites

\section{Background}

The lack of novel antibiotics in the pipeline of pharmaceutical companies and the simultaneous worldwide increase of antibiotic resistance represent enormous challenges in the re-emerging fight against infectious diseases [1]. In addition, the discovery of the complex functions of the human microbiome in maintaining health and its crucial contribution to the development of the immune system in infants call for completely new strategies [2]. As an alternative to killing the pathogens, quenching their quorum sensing mechanisms has been explored

\footnotetext{
* Correspondence: Irene.Wagner-Doebler@helmholtz-hzi.de

${ }^{1}$ Helmholtz-Center for Infection Research, Group Microbial Communication,

Inhoffenstr. 7, 38124 Braunschweig, Germany

Full list of author information is available at the end of the article
}

because resistance is expected to be very slow or unlikely. This is because the strategy does not interfere with growth and only changes its phenotype with minimal or no selective pressure [3-7]. For example, in $P$. aeruginosa, the cellcell communication required for establishing virulence was targeted. Mimics of its quorum sensing signal N-(3-oxododecanoyl)-L-homoserine lactone which were structurally similar to the natural AHL but unable to induce quorum sensing were synthesized and competed for the natural AHL resulting in reduced production of the virulence factor pyocyanin [8].

In this context, interest in compounds synthesized by bacteria, fungi, plants and animals has increased [9]. Myxobacteria are a particularly rich source of secondary metabolites [10] and have recently been found to yield various 
novel chemical entities that appear promising as starting points for development of novel antibiotics [11-13]. Natural compounds have unique, highly complex chemical structures and dedicated biosynthetic pathways and have been optimized in evolution for improving the survival of the producing organism; their biological function is therefore context dependent and often not known [14]. In particular from fungi, numerous novel unique metabolites are continuously being discovered, which may serve as basis for novel lead structures to combat bacterial pathogens [15]. For example, caspofungin, a semi-synthetic derivative of pneumocadin from Glarea lozoyensis, was active against Candida albicans biofilms and was the first fungal inhibitor that has been approved for treatment against invasive candidiasis [16]. Aspergillomarasmine A (AMA), from Aspergillus versicolor was recently identified to inhibit the function of metallo- $\beta$ - lactamase NDM-1 of Enterobacteriaceae. It sequestered the $\mathrm{Zn} 2+$ required activity of NDM-1 metalloproteinase, which opens the $\beta$ lactam ring of the antibiotic thereby causing resistance. However, AMA with its sequestration ability re-sensitizes bacteria to meropenem [17].

Here we focused on Streptococcus mutans, an important component of dental plaque. S. mutans was considered the etiological agent of caries based on cultivation-dependent analyses [18]. Current next generation sequencing approaches found $S$. mutans to be a minor component of caries lesions and revealed the contribution of many more oral species to caries development [19-22]. In fact Veillonella sp. was identified to be predictive of early childhood caries, but not $S$. mutans [23]. Here we use $S$. mutans as a model and test a general strategy that might be transferable to other streptococci. For this aim, S. mutans is ideally suited because it is very well studied and many genetic tools are available.

Here we now targeted the ability to produce mutacins, the peptide antibiotics synthesized by S. mutans [24]. According to their structure, they are divided into nonlantibiotics and lantibiotics, of which the lantibiotic mutacin 1140 has attracted large interest as anti-bacterial drug $[25,26]$. Previously a strain of $S$. mutans was developed that produced elevated levels of mutacin 1140 while being impaired in acid production [27, 28]. It was planned to be applied as a probiotic to outcompete wild-type $S$. mutans for the so-called replacement therapy of dental caries and underwent phase 1 clinical testing [29].

Here we pursued an alternative approach. Since mutacins kill competitors [30, 31], suppression of their synthesis should impair the fitness of $S$. mutans in the polymicrobial dental plaque biofilm. Natural compounds that suppress mutacin production might be more easily approved by the authorities than a genetically engineered probiotic. Therefore we developed whole-cell reporters of $S$. mutans UA159 where we fused the promoters of mutacin synthesis genes to the enhanced GFP+ and monitored fluorescence as a proxy of gene expression. Mutacin synthesis in $S$. mutans is under the control of the autoinducer MIP (mutacin inducing peptide) [32]. Thus we induced mutacin synthesis by MIP and monitored reduction of fluorescence in the presence of test compounds. In such a way we screened 297 natural compounds from myxobacteria and fungi, of which the most interesting compound was subsequently validated.

\section{Methods}

\section{Bacterial strains and cultivation conditions}

Escherichia coli DH5 $\alpha$ was grown aerobically in Luriani Bertani (LB) broth (Carl Roth, X969.2) at $37{ }^{\circ} \mathrm{C}$. Selection of positive clones in E. coli was done on LB plates with $1.5 \%$ agar and $300 \mu \mathrm{g} / \mathrm{ml}$ erythromycin (Sigma Aldrich, E5389). Overnight cultures of Streptococcus mutans UA159 (ATCC 700610) were routinely grown in Todd Hewitt broth supplemented with $0.5 \%(w / v)$ yeast extract (THBY; Becton Dickinson, 249,240, 212,750) at $37^{\circ}$ $\mathrm{C}$ and $5 \% \mathrm{CO}_{2}$ without shaking. $10 \mu \mathrm{g} / \mathrm{ml}$ of erythromycin was used for selection of positive clones on THBY agar. The indicator strains L. lactis for SMU_1914 and S. sanguinis for SMU_150 were routinely grown in THBY broth at $37^{\circ} \mathrm{C}$ and were overlaid with $0.7 \%$ THBY soft agar in the mutacin overlay assay. For screening, the mutacin expression reporters were grown on a semi-defined BM medium [33] where the concentration of glucose was increased to $0.5 \%$. BM medium was chosen because it had minimal background fluorescence.

\section{Construction of fluorescent reporter strains}

Plasmid pAE03 [34] was used for the construction of the mutacin expression reporters. The plasmid encodes an erythromycin cassette for selection and a promotorlessGFP+ fluorophore to which the respective mutacin promotors were fused. The promotors of the mutacin genes SMU.423 (mutacin VI), SMU.150 (mutacin IV) and SMU. 1914 (mutacin V) were amplified using fusion polymerase (New England Biolabs, M0530S) and the primers listed (see Additional file 1). PCR products were cloned into the plasmid pAE03 using the Clone EZ Genscript kit (L00339). The recombination reaction was carried out in a thermocycler at $22{ }^{\circ} \mathrm{C}$ for $30 \mathrm{~min}$. The mixture was transformed into E.coli DH5 $\alpha$ competent cells and clones were selected on THBY agar with $300 \mu \mathrm{g} / \mathrm{ml}$ erythromycin (Sigma Aldrich, E5389). From the positive clones, plasmids were purified, transformed into S. mutans UA159 and selected on THBY agar with $10 \mu \mathrm{g} / \mathrm{ml}$ of erythromycin. Positive clones where promoter and GFP+ were fused by single homologous recombination were confirmed by PCR and sequencing. 


\section{Construction of deletion mutants in S. mutans}

The mutacin genes were amplified from genomic DNA of $S$. mutans with specific primers (see Additional file 1). $5^{\prime}$ end of the forward and reverse primer for erythromycin, and P2/P3 sequences of the gene amplification primers were incorporated with restriction sites (AscI and FseI) to create overhangs for ligation. The amplified sequences were digested with the restriction enzymes AseI and FseI (New England biolabs, R0558S, R0588S). The digested fragments were purified using QIAquick PCR purification kit (28106). The concentration of the fragments was determined using nanodrop and confirmed by agarose gel electrophoresis. The digested erythromycin cassette and the flanking regions were ligated with T4 DNA ligase (New England biolabs, M0202). The ligation reaction was carried out at RT for $10 \mathrm{~min}$ followed by inactivation at $65{ }^{\circ} \mathrm{C}$ for $10 \mathrm{~min}$ in a thermocycler. The ligation product was transformed into $S$. mutans UA159 and positive clones were selected by $10 \mu \mathrm{g} / \mathrm{ml}$ of erythromycin. Deletion constructs were verified by PCR and sequencing.

\section{Transformation in E. coli and S. mutans}

Transformation in E. coli: SOC medium was thawed at $37^{\circ}$ $C$ and TSS solution was placed on ice. An overnight culture of $E$. coli DH5 $\alpha$ was diluted 1:100 in $5 \mathrm{ml}$ sterile LB broth and incubated at $37^{\circ} \mathrm{C}$ at $200 \mathrm{rpm}$ until an OD 0.3-0.4. $1 \mathrm{ml}$ of the culture was centrifuged (13,000 rpm, $1 \mathrm{~min})$, the supernatant was discarded and the pellet re-suspended in $100 \mu \mathrm{l}$ ice-cold TSS solution. The plasmid construct (5$10 \mu \mathrm{l})$ was added to the cells and incubated on ice for 30 min followed by a heat shock at $42{ }^{\circ} \mathrm{C}$ for 45 min with subsequent transfer to ice for $2 \mathrm{~min}$. The transformation mixture was transferred to $600 \mu \mathrm{lOC}$ medium and incubated for $1 \mathrm{~h}$ in the $37^{\circ} \mathrm{C}$ shaker. The cells were centrifuged $(10,000 \mathrm{rpm}, 2 \mathrm{~min})$ and $550 \mu \mathrm{l}$ of the SOC medium was removed. The pellet was re-suspended in the residual medium and plated on LB agar with antibiotics when needed. The plates were incubated at $37{ }^{\circ} \mathrm{C}$ overnight. Positive colonies were picked, cultivated in LB, DNA was isolated and the construct was verified by sequencing.

Transformation in S. mutans: An overnight culture of S. mutans was diluted 1:10 in $5 \mathrm{ml}$ THBY medium. The cells were incubated at $37{ }^{\circ} \mathrm{C}$ and $5 \% \mathrm{CO}_{2}$ for $2 \mathrm{~h} .5 \mu \mathrm{l}$ of $1 \mathrm{mM}$ MIP was added and further incubated at $37{ }^{\circ} \mathrm{C}$ for $30 \mathrm{~min} .200 \mu \mathrm{l}$ of the culture was placed in an Eppendorf tube, DNA was added and the cells were incubated for $3 \mathrm{~h}$. Selection of constructs was performed on THBY agar with the respective antibiotics. Positive clones were picked, cultivated in THBY, DNA was isolated and the constructs were verified by sequencing.

\section{Screen for suppression of mutacin expression}

The mutacin reporter strains (150p, 1914p and 423p with $g f p+)$ were cultivated in THBY broth with $10 \mu \mathrm{g} / \mathrm{ml}$ erythromycin overnight. $15 \mathrm{ml}$ of the cultures were harvested by centrifugation (Thermo scientific X1R, $6000 \mathrm{rpm}$, $15 \mathrm{~min}, 4^{\circ} \mathrm{C}$ ). The supernatant was decanted and pellets were gently re-suspended in $7 \mathrm{ml}$ of freshly prepared BMglucose medium using a pipette. The $\mathrm{OD}_{600}$ of the cultures was adjusted to 0.2 using the Ultrospec 3100 pro UV/VIS spectrophotometer.

The assay was performed with a final culture volume of $200 \mu \mathrm{l}$ per well on a 96 well optical bottom polystyrene black microtitre plate (Thermo Scientific, 165305). $0.5 \mu \mathrm{l}$ of $1 \mathrm{mM}$ mutacin inducing peptide (MIP) synthesized inhouse and $10 \mu \mathrm{l}$ of the test compounds solved in methanol or DMSO were added to each well. Wells with MIP but without test compound served as controls. Plates were incubated at $37{ }^{\circ} \mathrm{C}, 5 \% \mathrm{CO}_{2}$, without shaking, for 4 to $24 \mathrm{~h}$. Absorbance (P620/8 nm filter) and fluorescence (485 $\mathrm{nm}$ excitation/535 emission) were determined with a plate reader (Perkin Elmer, Victor ${ }^{3} 1420$ Multilabel Counter). For the KOM and MWIS libraries, the assay was performed in triplicate, the SAAR plates contained each compound once. Data are mean and standard deviation from two independent experiments for the KOM and MWIS libraries. Validation experiments were performed in triplicate assays and two biological replicates.

\section{Natural product libraries}

A total of 297 compounds were screened and were derived from three different natural product libraries which are named after the groups that provided them KOM (Microbial Communication, HZI, Germany), MWIS (Microbial Drugs, HZI, Germany) and SAAR (HelmholtzInstitute of Pharmaceutical Research, Saarbrücken, Germany).

In case of KOM and MWIS, the stocks of the compounds were provided in methanol. These libraries were screened at a final concentration of $5 \mu \mathrm{g}$ and $0.5 \mu \mathrm{g}$ per $\mathrm{ml}$ in triplicates. Compounds from SAAR were provided on a polypropylene micro-titre plate with $5 \mu \mathrm{l}$ of the compound at $1 \mathrm{mM}$ concentration in DMSO. Plates were stored at $-80{ }^{\circ} \mathrm{C}$. Shortly before screening, the plate was retrieved from $-80{ }^{\circ} \mathrm{C}$ and thawed at room temperature. To pool the compounds to the bottom, the plate was centrifuged in a microplate centrifuge (Thermo scientific Heraeus labofuge $400 \mathrm{R}$ ) at $1500 \mathrm{rpm}$ for $5 \mathrm{~min}$ and the compounds were transferred to an optical bottom polystyrene black microtitre plate for testing. The final concentration of the compounds from the SAAR library was $25 \mu \mathrm{M}$.

\section{Mutacin overlay assay}

Overnight cultures in THBY of S. mutans UA159 and the deletion mutants $\Delta 150, \Delta 1914$ and $\Delta 423$ were adjusted to $\mathrm{OD}_{600}$ of 0.2 . To each culture erinacine $\mathrm{C}$ (5 $\mu \mathrm{g} / \mathrm{ml})$ was added, incubated $(45 \mathrm{~min})$ and then 
centrifuged (7500 rpm, $5 \mathrm{~min}$ ). The supernatant was discarded and the pellet was re-suspended in $50 \mu \mathrm{l}$ fresh THBY. $2.5 \mu \mathrm{l}$ of each sample was spotted on THBY agar. The plates were incubated for 4-6 h. Afterwards, $2.5 \mu \mathrm{l}$ of $1 \mathrm{mM}$ MIP and $2.5 \mu \mathrm{l}$ of $0.2 \mathrm{mg} / \mathrm{ml}$ erinacine $C$ was added to the spot and incubated overnight. On the following day, overnight cultures of L. lactis and S. sanguinis were adjusted to an $\mathrm{OD}_{600}$ of 0.1 and cultivated for $2.5 \mathrm{~h}$. After $2.5 \mathrm{~h}, 100 \mu \mathrm{l}$ of the mid-log phase cultures was diluted in $6 \mathrm{ml}$ of $0.7 \%$ THBY top agar and overlaid. After $20 \mathrm{~h}$ incubation, the area of inhibition around each spot was measured.

\section{Results}

The mutacin VI reporter shows strong population wide expression upon induction by MIP

$S$. mutans produces the three non-lantibiotic mutacins IV, V and VI. Mutacin IV, which is also termed NlmAB, acts against many streptococcal strains, while mutacin $\mathrm{V}$ (also termed NlmC or CipB) is active against nonstreptococcal species [35]. The activity of mutacin VI was only detected in a strain overexpressing the novel regulatory system BrsRM $[36,37]$ and thus no natural indicator strain is known. In spite of this lack of knowledge, we initially used the mutacin VI (SMU.423) reporter for screening because natural compounds might have elicited strong responses and this would have been an important novel finding. The fully induced reporter construct showed the same growth as the wild-type (see Additional file 2) indicating that the expression of GFP+ did not represent a metabolic burden and should not affect screening results. As expected, transcription of mutacin VI occurred in a population wide manner in THBY upon induction by MIP (Fig. 1). Transcription of all mutacin genes is controlled by the response regulator ComE which is activated directly through the ComDE two-component system [32]. Deletion of the mutacin VI open reading frame had no influence on growth (see Additional file 3).

\section{Prescreening for inhibitors of mutacin VI transcription}

Altogether 297 natural compounds were used for prescreening the mutacin VI reporter strain. They contained fungal and myxobacterial secondary metabolites and were available as DMSO or methanol stocks, large fraction of which were provided in microtiter format at $25 \mu \mathrm{M}$ [38]. Compounds were scored positive if they reduced the transcription of the maximally induced mutacin VI gene by more than $50 \%$ at three time-points without a strong effect on growth $\left(\mathrm{OD}_{600}>90 \%\right.$ of control induced by MIP but not treated by natural compound). Three time points were measured (t1, t2 and $\mathrm{t} 3$ in Table 1), namely at 4 or $6 \mathrm{~h}, 8 \mathrm{~h}$ and $24 \mathrm{~h}$. The time points were chosen because mutacin production remains high during the onset of stationary phase or when the cell density reaches maximum. They represented exponential growth (between 4 and $6 \mathrm{~h}$ ), onset of stationary phase $(8 \mathrm{~h})$ and stationary growth phase $(>8 \mathrm{~h}$ up to $24 \mathrm{~h}$ ). Of the 297 compounds, 49 inhibited growth, and 18 showed strong background fluorescence. From the remaining 230 compounds, 7 were scored positive (Table 1). The strongest inhibitor was myxovirescin $\mathrm{D}$ which reduced reporter fluorescence to $13 \%$ of the control. Interestingly, variants of ambruticin, an anti-fungal compound [39] were able to increase the expression of the fully induced mutacin VI promoter even further ( $>25 \%)$.

\section{Erinacine $\mathrm{C}$ inhibits transcription of all three mutacins of S. mutans UA159}

From the seven compounds shown in Table 1 we chose erinacine $\mathrm{C}$ for further investigations. First, we tested if the results of the prescreening could be confirmed in

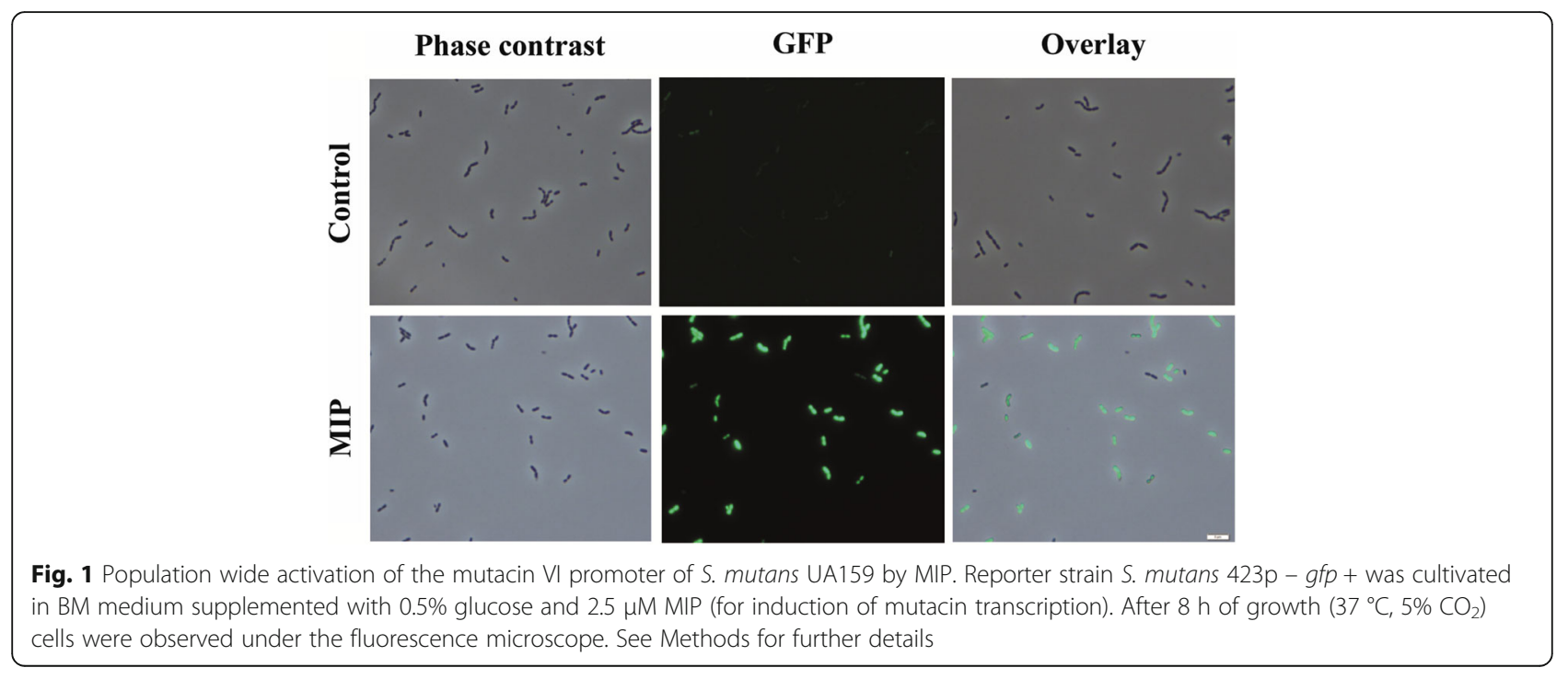


Table 1 Prescreening results for suppressors of mutacin VI transcription

\begin{tabular}{|c|c|c|c|c|c|}
\hline \multirow[t]{2}{*}{ Compound } & \multicolumn{3}{|c|}{$\%$ fluorescence } & \multirow[t]{2}{*}{ Structure } & \multirow[t]{2}{*}{ References } \\
\hline & t1 & t2 & t3 & & \\
\hline Erinacine $C$ & 43 & 38 & 40 & & {$[47]$} \\
\hline Noricumazol A & 33 & 29 & 24 & & {$[42,54,55]$} \\
\hline Myxovirescin D & 26 & 18 & 13 & & [43] \\
\hline Chondrochloren B & 47 & 38 & 25 & & {$[56,57]$} \\
\hline Aurachin A & 40 & 26 & 16 & & {$[44,58,59]$} \\
\hline Myxopyronin A & 23 & 20 & 27 & & {$[45,60-62]$} \\
\hline Jerangolid E & 42 & 42 & 35 & & {$[46,63]$} \\
\hline
\end{tabular}

Compounds that reduced fluorescence of the mutacin VI reporter at three time points $(\mathrm{t} 1, \mathrm{t} 2, \mathrm{t} 3)$ by more than $50 \%$ without affecting growth (less than $10 \%$ reduction in $\mathrm{OD}_{600}$ ) are shown here. The total number of tested compounds was 297

laboratory culture. Then, we tested if this compound also suppressed the transcription of the two other mutacins of S. mutans. Mutacin IV is transcribed weakly and kills closely related Streptococci [35], while mutacin V is transcribed at much higher rates [32] and kills additionally Lactococcus species. To this end we used reporter strains 1914p - gfp + (for the promoter of SMU.1914, mutacin V) and reporter strain 150p - gfp + (for the promoter of SMU.150, mutacin IV). Figure 2 shows that at $5 \mu \mathrm{g} / \mathrm{ml}$ final concentration, erinacine $\mathrm{C}$ also reduced expression of mutacin IV and V, although the strength of inhibition varied. There was no growth inhibition at this concentration. Lower concentrations of erinacine $\mathrm{C}$ were inactive (Fig. 2, Additional file 4). At higher concentrations of erinacine $C$, growth was increasingly impaired (Additional file 4). At $20 \mu \mathrm{g} / \mathrm{ml}$ erinacine $\mathrm{C}$, growth of the $S$. mutans reporter strains was reduced to approximately $50 \%$ of the controls.

\section{Erinacine $\mathrm{C}$ protects indicator strains from killing by $\mathrm{S}$. mutans}

Post-transcriptional regulatory mechanisms have a large influence on the expression of proteins and peptides, and play a particularly important role for the synthesis and maturation especially of bacteriocins. For example, in $S$. mutans transcription of mutacin $\mathrm{V}$ is induced in 


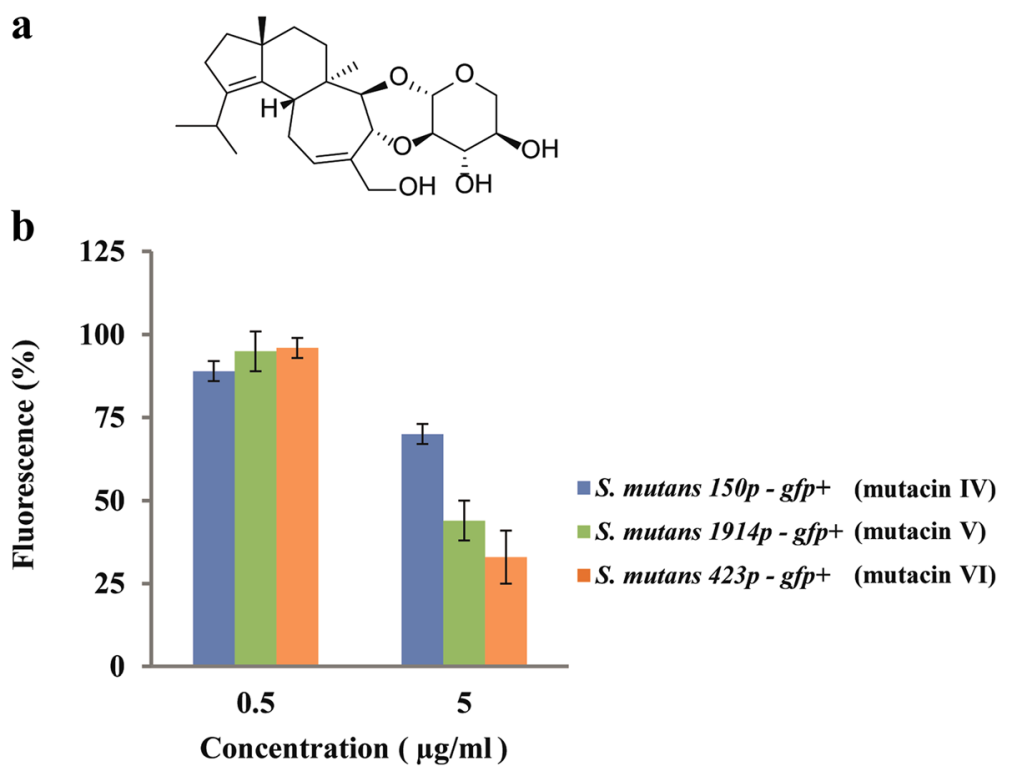

Fig. 2 Reduction of mutacin IV, V and VI expression by erinacine C. Upper panel a: Chemical structure of erinacine C [47]. Lower panel b: Reporter strains 150p, 1914p and 423p (tagged with $g f p+$ ) were cultivated as in Fig. 1, except that erinacine C was added at the same time as MIP at $0.5 \mu \mathrm{g} / \mathrm{ml}$ or $5 \mu \mathrm{g} / \mathrm{ml}$ (final concentration). Data show mean and standard deviation of two biological replicates which were conducted with triplicate subsamples

minimal medium, yet the active bacteriocin was not detectable [32]. Therefore we investigated if erinacine $\mathrm{C}$ could reduce the amount of mutacins produced by $S$. mutans. We first determined the sensitivity of the sensor strains Lactococcus lactis and S. sanguinis against the three mutacins of $S$. mutans. To this end we constructed gene deletion mutants for each of the three mutacins and tested how growth of the sensor strains L. lactis and S. sanguinis was influenced by these mutants. Additional file 5 shows that L. lactis was killed mainly by mutacin V and S. sanguinis mainly by mutacin IV, as expected. Deletion of SMU.423 had no influence on the zone of inhibition of both strains, confirming that mutacin VI is either not produced, or is not active against these two sensor strains.

Finally we incubated the wild-type $S$. mutans UA159 with erinacine $\mathrm{C}$. Figure 3 shows an example for the area of inhibition, and Table 2 shows the data from all experiments. The area of inhibition for S. sanguinis was reduced from $162 \pm 24 \mathrm{~mm}^{2}$ to $106 \pm 9 \mathrm{~mm}^{2}$ in the presence of erinacine $\mathrm{C}$, representing 35\% reduction. The effect on $L$. lactis, indicator for the highly expressed mutacin $\mathrm{V}$, was even stronger ( $42 \%$ reduction of the area of inhibition). In the presence of MIP, the inhibition areas increased for both sensor strains as expected. Interestingly, addition of MIP increased the effect of erinacine C: If both erinacine $\mathrm{C}$ and MIP were applied, the area of inhibition was reduced by $47 \%$ for $S$. sanguinis and by $61 \%$ for L. lactis. The data show that erinacine $C$ not only inhibited the transcription of mutacins, but the amount of the mature, active mutacin antibiotics in the cultivation medium was reduced in comparison to the untreated $S$. mutans UA159 culture. As a result, killing of the sensor strains was reduced. We hypothesize that erinacine $\mathrm{C}$ might similarly inhibit the synthesis of mutacins in dental plaque. $S$. mutans would therefore be less dangerous to competing bacteria and have a reduced fitness. The findings of our study support future studies aimed at evaluating the loss of virulence in a plaque/biofilm study.

\section{Discussion}

Pharmaceutical industry has in the past routinely been using screens based on purified enzymes in high-throughput, triggered by comparative genomics which allowed identifying potential drug targets [40]. Although these screens can be automatized and used for testing huge synthetic libraries, the number of hits that were able to act on whole cells was disappointingly small (e.g. [41]). Using wholecell screens has the advantage of finding only those molecules that are active against live cells. The disadvantage is that such screens are not easily automated and miniaturized, results depend on the physiological state of the cells, and most importantly, the mode of action of the compound and its molecular target remain unknown.

The seven compounds discovered here to inhibit mutacin transcription belong to completely different chemical classes of secondary metabolites (Table 1), thus they most probably reduce transcription of mutacins by different mechanisms. They also have entirely different modes of action: Noricumazol is a cation channel blocker [42], 


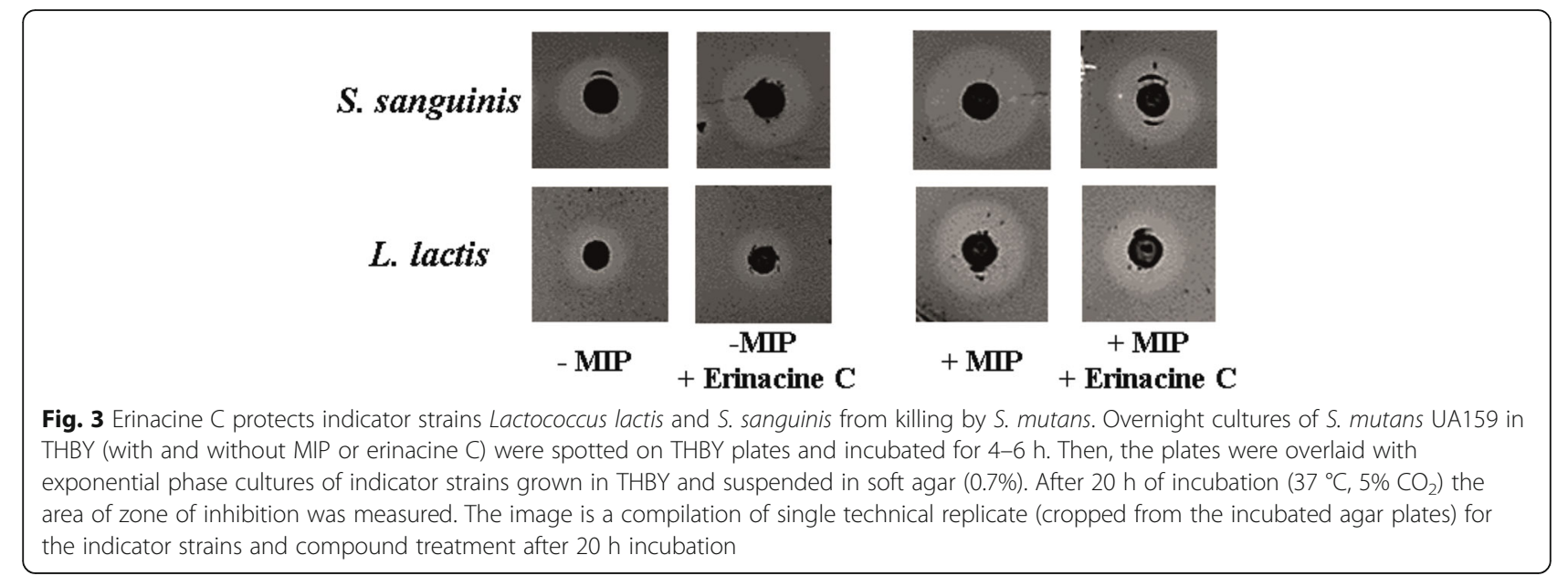

myxovirescin interferes with cell-wall synthesis [43], aurachin blocks the respiratory chain [44], and myxopyronin is an inhibitor of RNA polymerase [45]. The modes of action are unknown for chondrochloren and jerangolid, although the latter has been reported to change membrane permeability of the yeast Hansenula anomala [46]. The activity of the compounds on the mutacin reporter strains therefore most likely represents a secondary effect and the exact mechanism would have to be determined.

Erinacines are cyathane diterpenes produced by mycelial cultures of the edible and medicinal mushroom Hericium erinaceus and were originally reported to stimulate nerve growth factor biosynthesis [47]. The fruiting bodies as well as the mycelia of this species have been studied intensively in the past decades, and the most important findings were recently compiled in a review [48]. The compounds tested in the current study were derived from a project that recently resulted in the discovery of the novel corallocins from the related species, Hericium coralloides [49]. However, these neurotropic metabolites, as well as several other metabolites obtained from cultures and basidiomata of Hericium species, were found devoid of activities in the present study. Erinacine $\mathrm{C}$ is presently being prepared in large quantities by fermentation to further elucidate its biochemical mode of action and to further characterise its antiinfective and neurotropic activity.

In this study, erinacine $\mathrm{C}$ was demonstrated to suppress mutacin synthesis in $S$. mutans which defines a new biological activity for this molecule. No other study on the activity of erinacine $C$ on bacteria was found, except one which reported a weak inhibition of $S$. mutans by extracts from $H$. erinaceus in a disc diffusion assay [50]. To show that reduction of mutacin biosynthesis by erinacine $\mathrm{C}$ reduces the fitness of $S$. mutans in vivo, it would be necessary to study the effect of this compound on the survival of $S$. mutans in multi-species oral biofilm models [51] or dental plaque communities.

Interestingly, erinacine $C$ reduced the transcription of all three mutacins of $S$. mutans, and synthesis and maturation of at least two of them. Therefore the target of erinacine $\mathrm{C}$ must be upstream of the individual synthesis genes and common for all three mutacins. The mutacin synthesis in $S$. mutans is regulated by the two-component system ComDE and the quorum sensing signal MIP (mutacin inducing peptide) [32]. The signaling molecule MIP is secreted into the environment, and after reaching a certain concentration binds to the transmembrane histidine kinase ComD. This leads to the phosphorylation of its cognate cytoplasmic response regulator ComE. Transcription of all three mutacins is initiated by binding of phosphorylated ComE to specific promoter regions in the bacteriocin genes. Since transcription of all three mutacins was supressed by erinacine $\mathrm{C}$, we hypothesize that this compound interacted with the ComDE signalling cascade. It would be interesting to investigate this hypothesis to see if erinacine $C$ interferes with ComDE of $S$. mutans, and if it possibly interferes with two-component systems of other bacteria, which would

Table 2 Reduced killing of mutacin IV and V indicator strains in the presence of erinacine C

\begin{tabular}{|c|c|c|c|c|}
\hline \multirow[b]{2}{*}{ Indicator strain } & \multicolumn{4}{|c|}{ Treatment } \\
\hline & control & + Erinacine $\mathrm{C}$ & $+\mathrm{MIP}$ & + Erinacine $\mathrm{C}+\mathrm{MIP}$ \\
\hline Streptococcus sanguinis & $162 \pm 24$ & $106 \pm 9$ & $239 \pm 31$ & $128 \pm 12$ \\
\hline Lactococcus lactis & $121 \pm 13$ & $71 \pm 8$ & $168 \pm 24$ & $66 \pm 6$ \\
\hline
\end{tabular}

Erinacine $C$ was provided to $S$. mutans at $5 \mu \mathrm{g} / \mathrm{ml}$ final concentration, and MIP at $2.5 \mu \mathrm{g} / \mathrm{ml}$ final concentration. $S$. sanguinis is a specific indicator stain for mutacin IV, and Lactococcus lactis for mutacin V. See Methods for details on overlay assay. The area of the zone of inhibition was calculated and the data are mean and standard deviation of three biological replicates 
make it an interesting anti-virulence molecule. Previously walkmycin, a complex secondary metabolite from Streptomyces sp., was shown to inhibit autophosphorylation of histidine kinases of $S$. mutans UA159 and thus reduce its virulence $[52,53]$.

\section{Conclusion}

In this study, we demonstrated that a reporter strain for a gene that is important in terms of the ecology of the organism can be a useful screening tool. The observed reduction of mutacin synthesis might impair the survival of $S$. mutans in dental plaque and thus its virulence, but further studies are needed to show this. The strategy could be applied to other pathogens and other genes of interest.

\section{Additional files}

Additional file 1: Primers used in this study and their use. (DOCX $16 \mathrm{~kb}$ ) Additional file 2: Growth of reporter strains S. mutans 150p, P1914p and 423p (with $g f p+$ ). gfp + tagged reporter strains for 150p (A), 1914p (B) and $423 \mathrm{p}(\mathrm{C})$ were cultivated in BM medium on a microtitre plate at $37{ }^{\circ} \mathrm{C}, 5 \% \mathrm{CO}_{2}$ and monitored for growth (OD 620 ) using a VICTOR plate reader from 0 to $8 \mathrm{~h}$ and $24 \mathrm{~h}$. Data represent the mean and standard deviation of two biological replicates which were conducted with triplicate subsamples. (TIFF $893 \mathrm{~kb}$ )

Additional file 3: Growth of S. mutans UA159 $\Delta 423$. Knock-out strains for mutacin encoding genes were created by replacing genes with erythromycin $B$ cassette and the growth (OD ${ }_{600}$ ) was monitored in THBY. Data show the mean and standard deviation of a biological replicate which were conducted with triplicate subsamples. (TIFF 848 kb)

Additional file 4: Concentration dependent inhibition of mutacin transcription by erinacine $C$. Reporter strains for bacteriocin gene expression 150p, 1914p and 423p were cultivated as in Fig. 1, and erinacine $C$ was added at the indicated final concentrations. Growth and fluorescence are shown in \% of the control (reporter strain induced by MIP). Data show mean and standard deviation of two biological replicates which were conducted with triplicate subsamples. (TIFF $1151 \mathrm{~kb}$ )

Additional file 5: Mutacin overlay assay to determine the specificity of the sensor strains. Overnight cultures of wild-type and knock-out strains for mutacins of S. mutans UA159 were spotted on THBY agar and allowed to incubate for 4-6 h. The exponential cultures of indicator strains $S$. sanguinis and $L$. lactis were overlaid on the plates using $0.7 \%$ agar. The area of zone of inhibition was measured after $20 \mathrm{~h}$ of incubation. (TIFF $1398 \mathrm{~kb}$ )

\footnotetext{
Abbreviations

AHL: acylated homoserine lactone; AMA: Aspergillomarasmine A.; BM: Biofilm medium; DMSO: Dimethyl-sulfoxide; DNA: Ddesoxyribonucleic acid; GFP: Green fluorescent protein; HZI: Helmholtz-Center for Infection Research; KOM: Natural compound library from the research group "Microbial Communication" (KOM) at the Helmholtz-Center for Infection Research; LB: Luria Bertani; MIP: Mutacin inducing peptide; MWIS : Natural compound library from the department Microbial Drugs (MWIS), Helmholtz-Center for Infection Research, Germany; NDM-1: Metalloproteinase; OD: Optical density; PCR: Polymerase chain reaction; rpm: Rounds per minute; RT: Room temperature; SAAR: Natural compound library from the Helmholtz-Institute of Pharmaceutical Research, Saarbrücken, Germany; SOC: Medium used in the last step of transformation; THBY: Todd Hewitt broth supplemented with $0.5 \%(w / v)$ yeast extract; TSS: Buffer to make chemically competent cells; VICTOR: Multilabel fluorescent plate reader
}

\section{Acknowledgements}

We thank Bettina Elxnat for excellent technical assistance. We are grateful to Dr. Jennifer Herrmann, Dr. Rolf Jansen, Ms. Kerstin Schober and Ms. Viktoria Schmitt for supplying the library compounds.

\section{Funding}

This work was funded by a grant for PP from the MINAS Graduate School and by the German Ministry for Research and Technology (BMBF) in the program e:bio (grant number 031299A). The funders had no role in the design of the study, collection, analysis and interpretation of data and writing the manuscript.

\section{Availability of data and materials}

The datasets analysed during the current study are available from the corresponding author upon reasonable request.

\section{Authors' contributions}

PP conducted the experiments and wrote the draft of the paper; MR provided strains and supervised laboratory work; KW provided compounds for testing; IWD designed the study; MS and IWD finalized the manuscript. All authors analysed and interpreted the data, were involved in drafting the manuscript and revising it critically, gave final approval of the version to be published, and agreed to be accountable for all aspects of the work.

Ethics approval and consent to participate Not applicable.

\section{Consent for publication}

Not applicable.

\section{Competing interests}

The authors declare that they have no competing interests.

\section{Publisher's Note}

Springer Nature remains neutral with regard to jurisdictional claims in published maps and institutional affiliations.

\section{Author details}

${ }^{1}$ Helmholtz-Center for Infection Research, Group Microbial Communication, Inhoffenstr. 7, 38124 Braunschweig, Germany. ${ }^{2}$ Helmholtz-Center for Infection Research, Department of Microbial Drugs, Inhoffenstr. 7, 38124 Braunschweig, Germany.

Received: 16 August 2017 Accepted: 20 March 2018

Published online: 27 March 2018

References

1. Silver LL. Challenges of antibacterial discovery. Clin Microbiol Rev. 2011;24: 71-109.

2. Heras $B$, Scanlon MJ, Martin JL. Targeting virulence not viability in the search for future antibacterials. Br J Clin Pharmacol. 2015;79:208-15.

3. Gill EE, Franco OL, Hancock RE. Antibiotic adjuvants: diverse strategies for controlling drug-resistant pathogens. Chem Biol Drug Des. 2015;85:56-78.

4. Hentzer M, Riedel K, Rasmussen TB, Heydorn A, Andersen JB, Parsek MR Rice SA, Eberl L, Molin S, Hoiby N, Kjelleberg S, Givskov M. Inhibition of quorum sensing in Pseudomonas aeruginosa biofilm bacteria by a halogenated furanone compound. Microbiology (Reading, England) 2002;148:87-102.

5. Hentzer M, Wu H, Andersen JB, Riedel K, Rasmussen TB, Bagge N, Kumar N, Schembri MA, Song Z, Kristoffersen P, Manefield M, Costerton JW, Molin S, Eberl L, Steinberg P, Kjelleberg S, Hoiby N, Givskov M. Attenuation of Pseudomonas aeruginosa virulence by quorum sensing inhibitors. EMBO J. 2003;22:3803-15.

6. Rasko DA, Sperandio V. Anti-virulence strategies to combat bacteriamediated disease. Nat Rev Drug Discov. 2010;9:117-28.

7. Sully EK, Malachowa N, Elmore BO, Alexander SM, Femling JK, Gray BM, DeLeo FR, Otto M, Cheung AL, Edwards BS, Sklar LA, Horswill AR, Hall PR, Gresham HD. Selective chemical inhibition of agr quorum sensing in Staphylococcus aureus promotes host defense with minimal impact on resistance. PLoS Pathog. 2014;10:e1004174. 
8. Morkunas B, Galloway WR, Wright M, Ibbeson BM, Hodgkinson JT, O'Connell KM, Bartolucci N, Della VM, Welch M, Spring DR. Inhibition of the production of the Pseudomonas aeruginosa virulence factor pyocyanin in wild-type cells by quorum sensing autoinducer-mimics. Org Biomol Chem. 2012;10:8452-64.

9. Harvey AL, Edrada-Ebel R, Quinn RJ. The re-emergence of natural products for drug discovery in the genomics era. Nat Rev Drug Discov. 2015;14:111-29.

10. Herrmann J, Fayad AA, Muller R. Natural products from myxobacteria: novel metabolites and bioactivities. Nat Prod Rep. 2017;34:135-60.

11. Baumann S, Herrmann J, Raju R, Steinmetz H, Mohr Kl, Huttel S, Harmrolfs K, Stadler M, Muller R. Cystobactamids: myxobacterial topoisomerase inhibitors exhibiting potent antibacterial activity. Angew Chem Int Ed Engl. 2014;53: 14605-9.

12. Surup F, Viehrig K, Mohr Kl, Herrmann J, Jansen R, Muller R. Disciformycins a and B: 12-membered macrolide glycoside antibiotics from the myxobacterium Pyxidicoccus fallax active against multiresistant staphylococci. Angew Chem Int Ed Engl. 2014;53:13588-91.

13. Schieferdecker S, Konig S, Weigel C, Dahse HM, Werz O, Nett M. Structure and biosynthetic assembly of gulmirecins, macrolide antibiotics from the predatory bacterium Pyxidicoccus fallax. Chemistry. 2014;20:15933-40.

14. Ji HF, Li XJ, Zhang HY. Natural products and drug discovery. Can thousands of years of ancient medical knowledge lead us to new and powerful drug combinations in the fight against cancer and dementia? EMBO Rep. 2009; 10:194-200.

15. Karwehl S, Stadler M. Exploitation of fungal biodiversity for discovery of novel antibiotics. Curr Top Microbiol Immunol. 2016;398:303-38.

16. Bachmann SP, VandeWalle K, Ramage G, Patterson TF, Wickes BL, Graybill JR, Lopez-Ribot JL. In vitro activity of caspofungin against Candida albicans biofilms. Antimicrob Agents Chemother. 2002;46:3591-6.

17. King AM, Reid-Yu SA, Wang W, King DT, De PG, Strynadka NC, Walsh TR, Coombes BK, Wright GD. Aspergillomarasmine A overcomes metallo-betalactamase antibiotic resistance. Nature. 2014;510:503-6.

18. Hamada S, Slade HD. Biology, immunology, and cariogenicity of Streptococcus mutans. Microbiol Rev. 1980;44:331-84.

19. Simon-Soro A, Guillen-Navarro M, Mira A. Metatranscriptomics reveals overall active bacterial composition in caries lesions. J Oral Microbiol. 2014:6:25443.

20. Simon-Soro A, Mira A. Solving the etiology of dental caries. Trends Microbiol. 2015;23:76-82.

21. Simon-Soro A, Belda-Ferre P, Cabrera-Rubio R, Alcaraz LD, Mira A. A tissuedependent hypothesis of dental caries. Caries Res. 2013:47:591-600.

22. Benitez-Paez A, Belda-Ferre P, Simon-Soro A, Mira A. Microbiota diversity and gene expression dynamics in human oral biofilms. BMC Genomics. 2014;15:311.

23. Teng F, Yang F, Huang $\mathrm{S}, \mathrm{Bo} C, \mathrm{Xu} Z \mathrm{ZZ}$, Amir A, Knight R, Ling J, Xu J. Prediction of early childhood caries via spatial-temporal variations of oral microbiota. Cell Host Microbe. 2015;18:296-306.

24. Merritt J, Qi F. The mutacins of Streptococcus mutans: regulation and ecology. Mol Oral Microbiol. 2012;27:57-69.

25. Chen S, Wilson-Stanford S, Cromwell W, Hillman JD, Guerrero A, Allen CA, Sorg JA, Smith L. Site-directed mutations in the lanthipeptide mutacin 1140 , Appl Environ Microbiol. 2013;79:4015-23.

26. Ongey EL, Yassi H, Pflugmacher S, Neubauer P. Pharmacological and pharmacokinetic properties of lanthipeptides undergoing clinical studies. Biotechnol Lett. 2017;39:473-82.

27. Hillman JD, Brooks TA, Michalek SM, Harmon CC, Snoep UL, van Der Weijden CC. Construction and characterization of an effector strain of Streptococcus mutans for replacement therapy of dental caries. Infect Immun. 2000;68:543-9.

28. Hillman JD. Genetically modified Streptococcus mutans for the prevention of dental caries. Antonie Van Leeuwenhoek. 2002;82:361-6.

29. Hillman JD, Mo J, McDonell E, Cvitkovitch D, Hillman CH. Modification of an effector strain for replacement therapy of dental caries to enable clinical safety trials. J Appl Microbiol. 2007;102:1209-19.

30. Kreth J, Merritt J, Shi W, Qi F. Competition and coexistence between Streptococcus mutans and Streptococcus sanguinis in the dental biofilm. J Bacteriol. 2005;187:7193-203.

31. Kreth J, Zhang Y, Herzberg MC. Streptococcal antagonism in oral biofilms: Streptococcus sanguinis and Streptococcus gordonii interference with Streptococcus mutans. J Bacteriol. 2008:190:4632-40.

32. Reck M, Tomasch J, Wagner-Dobler I. The alternative sigma factor SigX controls Bacteriocin synthesis and competence, the two quorum sensing regulated traits in Streptococcus mutans. PLoS Genet. 2015;11:e1005353.
33. Loo CY, Corliss DA, Ganeshkumar N. Streptococcus gordonii biofilm formation: identification of genes that code for biofilm phenotypes. J Bacteriol. 2000;182:1374-82.

34. Eberhardt A, Wu L, Errington J, Vollmer W, Veening JW. Cellular localization of choline-utilization proteins in Streptococcus pneumoniae using novel fluorescent reporter systems. Mol Microbiol. 2009;74:395-408.

35. Hossain MS, Biswas I. Mutacins from Streptococcus mutans UA159 are active against multiple streptococcal species. Appl Environ Microbiol. 2011;77:2428-34.

36. Okinaga T, Niu G, Xie Z, Qi F, Merritt J. The hdrRM operon of Streptococcus mutans encodes a novel regulatory system for coordinated competence development and bacteriocin production. J Bacteriol. 2010;192:1844-52.

37. Xie Z, Okinaga T, Niu G, Qi F, Merritt J. Identification of a novel bacteriocin regulatory system in Streptococcus mutans. Mol Microbiol. 2010;78:1431-47.

38. Maurer CK, Fruth M, Empting M, Avrutina O, Hossmann J, Nadmid S, Gorges J, Herrmann J, Kazmaier U, Dersch P, Muller R, Hartmann RW. Discovery of the first small-molecule CsrA-RNA interaction inhibitors using biophysical screening technologies. Future Med Chem. 2016;8:931-47.

39. Knauth $\mathrm{P}$, Reichenbach $\mathrm{H}$. On the mechanism of action of the myxobacterial fungicide ambruticin. J Antibiot (Tokyo). 2000;53:1 182-90.

40. Payne DJ, Gwynn MN, Holmes DJ, Pompliano DL. Drugs for bad bugs: confronting the challenges of antibacterial discovery. Nat Rev Drug Discov. 2007:6:29-40.

41. Eadsforth TC, Gardiner M, Maluf FV, McElroy S, James D, Frearson J, Gray D, Hunter WN. Assessment of Pseudomonas aeruginosa N5,N10methylenetetrahydrofolate dehydrogenase-cyclohydrolase as a potential antibacterial drug target. PLoS One. 2012;7:e35973.

42. Barbier J, Jansen R, Irschik H, Benson S, Gerth K, Bohlendorf B, Hofle G Reichenbach H, Wegner J, Zeilinger C, Kirschning A, Muller R. Isolation and total synthesis of icumazoles and noricumazoles-antifungal antibiotics and cation-channel blockers from Sorangium cellulosum. Angew Chem Int Ed Engl. 2012;51:1256-60.

43. Gerth $\mathrm{K}$, Irschik $\mathrm{H}$, Reichenbach $\mathrm{H}$, Trowitzsch W. The myxovirescins, a family of antibiotics from Myxococcus virescens (Myxobacterales). J Antibiot (Tokyo). 1982;35:1454-9.

44. Kunze B, Hofle $G$, Reichenbach $H$. The aurachins, new quinoline antibiotics from myxobacteria: production, physico-chemical and biological properties. J Antibiot (Tokyo). 1987:40:258-65.

45. Belogurov GA, Vassylyeva MN, Sevostyanova A, Appleman JR, Xiang AX, Lira R, Webber SE, Klyuyev S, Nudler E, Artsimovitch I, Vassylyev DG. Transcription inactivation through local refolding of the RNA polymerase structure. Nature. 2009;457:332-5.

46. Gerth K, Washausen P, Hofle G, Irschik H, Reichenbach H. The jerangolids: a family of new antifungal compounds from Sorangium cellulosum (Myxobacteria). Production, physico-chemical and biological properties of jerangolid a. J Antibiot (Tokyo). 1996;49:71-5.

47. Kawagishi H, Shimada A, Shirai R, Okamoto K, Ojima F, Sakamoto H, Ishiguro $Y$, Furukawa $S$. Erinacines $A, B$ and $C$, strong stimulators of nerve growth factor (NGF) synthesis, from the mycelia of Hericium erinaceum. Tetrahedron Lett. 1994;35:1569-72.

48. Thongbai B, Rapior S, Wittstein K. Hyde KD, Stadler M. Hericium erinaceus, an amazing medicinal mushroom. Mycol Progr. 2015;14:1-23.

49. Wittstein K, Rascher M, Rupcic Z, Lowen E, Winter B, Koster RW, Stadler M. Corallocins A-C, nerve growth and brain-derived neurotrophic factor inducing metabolites from the mushroom Hericium coralloides. J Nat Prod. 2016;79:2264-9.

50. Han S, Jun J, Yang H, Oh T. Comparison of physiological activity of solvent extracts from Hericium erinaceus. Ind J Sci \& Tech. 2015;8

51. Schlafer S, Raarup MK, Meyer RL, Sutherland DS, Dige I, Nyengaard JR, Nyvad B. pH landscapes in a novel five-species model of early dental biofilm. PLoS One. 2011;6:e25299.

52. Okada A, Igarashi M, Okajima T, Kinoshita N, Umekita M, Sawa R, Inoue K, Watanabe T, Doi A, Martin A, Quinn J, Nishimura Y, Utsumi R. Walkmycin B targets WalK (YycG), a histidine kinase essential for bacterial cell growth. J Antibiot (Tokyo). 2010;63:89-94.

53. Eguchi $Y$, Kubo N, Matsunaga $H$, Igarashi M, Utsumi R. Development of an antivirulence drug against Streptococcus mutans: repression of biofilm formation, acid tolerance, and competence by a histidine kinase inhibitor, walkmycin C. Antimicrob Agents Chemother. 2011;55:1475-84.

54. Barbier J, Wegner J, Benson S, Gentzsch J, Pietschmann T, Kirschning A. Total synthesis of a noricumazole a library and evaluation of HCV inhibition. Chemistry. 2012;18:9083-90. 
55. Beck S, Henss L, Weidner T, Herrmann J, Muller R, Chao YK, Grimm C, Weber C, Sliva K, Schnierle BS. Identification of entry inhibitors of Ebola virus pseudotyped vectors from a myxobacterial compound library. Antivir Res. 2016;132:85-91.

56. Rachid S, Scharfe M, Blocker H, Weissman KJ, Muller R. Unusual chemistry in the biosynthesis of the antibiotic chondrochlorens. Chem Biol. 2009;16:70-81.

57. Zaburannyi N, Bunk B, Maier J, Overmann J, Muller R. Genome analysis of the fruiting body-forming Myxobacterium Chondromyces crocatus reveals high potential for natural product biosynthesis. Appl Environ Microbiol. 2016;82:1945-57.

58. Pistorius D, Li Y, Sandmann A, Muller R. Completing the puzzle of aurachin biosynthesis in Stigmatella aurantiaca sg a15. Mol BioSyst. 2011;7:3308-15.

59. Enomoto M, Kitagawa W, Yasutake Y, Shimizu H. Total synthesis of aurachins $C, D$, and $L$, and a structurally simplified analog of aurachin C. Biosci Biotechnol Biochem. 2014:78:1324-7.

60. Irschik H, Gerth K, Hofle G, Kohl W, Reichenbach H. The myxopyronins, new inhibitors of bacterial RNA synthesis from Myxococcus fulvus (Myxobacterales). J Antibiot (Tokyo). 1983;36:1651-8.

61. Doundoulakis T, Xiang AX, Lira R, Agrios KA, Webber SE, Sisson W, Aust RM, Shah AM, Showalter RE, Appleman JR, Simonsen KB. Myxopyronin B analogs as inhibitors of RNA polymerase, synthesis and biological evaluation. Bioorg Med Chem Lett. 2004;14:5667-72.

62. Moy TI, Daniel A, Hardy C, Jackson A, Rehrauer O, Hwang YS, Zou D, Nguyen K, Silverman JA, Li Q, Murphy C. Evaluating the activity of the RNA polymerase inhibitor myxopyronin B against Staphylococcus aureus. FEMS Microbiol Lett. 2011;319:176-9.

63. Julien B, Tian ZQ, Reid R, Reeves CD. Analysis of the ambruticin and jerangolid gene clusters of Sorangium cellulosum reveals unusual mechanisms of polyketide biosynthesis. Chem Biol. 2006;13:1277-86.

\section{Submit your next manuscript to BioMed Central and we will help you at every step:}

- We accept pre-submission inquiries

- Our selector tool helps you to find the most relevant journal

- We provide round the clock customer support

- Convenient online submission

- Thorough peer review

- Inclusion in PubMed and all major indexing services

- Maximum visibility for your research

Submit your manuscript at www.biomedcentral.com/submit

C) Biomed Central 